\title{
New Evaluation Techniques of Segregation in Continuously Cast Steel*
}

\section{By Ko MIYAMURA,** Isamu TAGUCHI ${ }^{* * *}$ and Hiromu SOGA**}

\begin{abstract}
Synopsis
For new precise evaluation techniques of segregation in continuously cast steel, Macroanalyser and Computer-aided Micro-analyser were developed by $R \& D$ Laboratories-I and-III of Nippon Steel Corp. These techniques, based on the analytical principle of an EPMA (an electron probe microanalyser), can present the spacious two-dimensional maps of the concentration of segregated elements such as $\mathrm{Mn}, \mathrm{P}, \mathrm{C}$ etc. and can offer the quantitative information on the fractions of segregated area and the size distribution of segregation spots corresponding to optional concentration of segregated elements. Therefore, these are useful enough to clarify the mechanism of segregation, the operational conditions for the control of the segregation and what factors of segregation are related to the quality of products.

In addition to these quantitative methods, the segregation etch print technique, by which the segregation can be easily and rapidly detected and recorded in very wide area of the inspection surfaces of big specimens with an excellent resolving power even for low sulphur content steel or $\mathrm{Ca}$ added steel, has been developed by Yawata $R \& D$ Lab. of Nippon Steel Corp. and is now in use for the inspection of continuously cast slabs instead of the conventional methods like Baumann print.
\end{abstract}

\section{Introduction}

In these years, the refining technique of molten steel has been remarkably progressed, and high purity steel with very low $\mathrm{S}$ and $\mathrm{P}$ contents less than $10 \sim$ $20 \mathrm{ppm}$ comes to be commercially produced. Besides, the countermeasure against segregation in continuous casting process is now improving. As a result, the production of high grade steel by $\mathrm{CG}$ process is being realised and will increase considerably in the future. But, in high grade steel, segregation is apt to introduce serious problems and brings about much influence on the quality of products.

Especially, demand for good hydrogen induced cracking resistance and low temperature ductility is getting more severe year by year. Besides, process revolutions such as control rolling and hot charging are now advancing.

Therefore, the permitted limit of segregation is getting severe. In other words, even a little segregation in concentration and size becomes a problem. The shapes and the distributions of sulphide etc. become more important in high grade steel than in low one. In order to evaluate precisely such segregation, Baumann print (sulphur print) is no longer useful for the steel with low $\mathrm{S}$ content and $\mathrm{Ca}$ added steel. And the warm hydrochloric acid etching method is insufficient because of the poor resolving power and for want of quantitative function. On the other hand, $\mathrm{V}$ shape and spot segregation other than the central one may come into question. So, only limited information of EPMA seems to be inadequate. In the production of high grade steel by GG process, therefore, a new quantitative evaluation method of segregation is considered to be indispensable in spacious area with the good representability and the close relation to the quality of products.

Nippon Steel Corporation has developed and applied various new techniques shown in Table 1 and

Table 1. New evaluation techniques developed by NSC.

\begin{tabular}{|c|c|c|c|c|}
\hline New Technique & $\begin{array}{c}\text { Developer } \\
\text { (co-developer) }\end{array}$ & Principle & & Chracteristic \\
\hline $\begin{array}{l}\text { Macro-analyser } \\
\text { (MA) }\end{array}$ & $\begin{array}{l}\mathrm{R} \& \mathrm{D} \text { Laborato- } \\
\text { ries-III of NSC } \\
\text { (SEIKO I \& E) }\end{array}$ & \multirow{2}{*}{$\begin{array}{l}\text { Spectroscopy of } \\
\text { X-ray generated by } \\
\text { electron probe }\end{array}$} & 1) & $\begin{array}{l}\text { Two-dimensional quantitative analysis of many } \\
\text { elements in spacious coarse sample surface } \\
\text { Presentation of various informations by computer } \\
\text { processing }\end{array}$ \\
\hline $\begin{array}{l}\text { Computer-aided } \\
\text { Micro-analyser } \\
\text { (GMA) }\end{array}$ & $\begin{array}{l}\mathrm{R} \& \mathrm{D} \text { Laborato- } \\
\text { ries-I of NSG } \\
\text { (JEOL) }\end{array}$ & & 1) & $\begin{array}{l}\text { Two-dimensional quantitative analysis of many } \\
\text { elements in spacious sample surface } \\
\text { Spacious analysis of precipitate by high resolving } \\
\text { power } \\
\text { Same as above-mentioned 2) }\end{array}$ \\
\hline $\begin{array}{l}\text { Segregation Etch } \\
\text { Print (EP) }\end{array}$ & $\begin{array}{l}\text { Yawata R \& D } \\
\text { Lab. of NSG }\end{array}$ & $\begin{array}{l}\text { Segregation etching } \\
\mid \rightarrow \text { printing }\end{array}$ & $\begin{array}{l}\text { 2) } \\
\text { 3) }\end{array}$ & $\begin{array}{l}\text { Quick and convenient evaluation of very spacious } \\
\text { inspection surface } \\
\text { Good preservation } \\
\text { Quasi-quantitative evaluation by picture analysis } \\
\text { is possible. }\end{array}$ \\
\hline
\end{tabular}

* Based on the paper presented to the symposium of the 106th ISIJ Meeting, October 1983, at Akita University in Akita, (published in Tetsu-to-Hagané, 69 (1983), A197, in Japanese). Manuscript received March 8, 1984. (C) 1984 ISIJ

** Yawata R \& D Laboratory, Nippon Steel Corporation, Edamitsu, Yahatahigashi-ku, Kitakyushu 805.

*** R \& D Laboratories-I, Nippon Steel Corporation, Ida, Nakahara-ku, Kawasaki 211. 
is now promoting the production of high grade steel by $\mathrm{CC}$ process through the researches on the relations of segregation, product quality and operation conditions.

\section{Necessary Functions for New Evaluation Techniques}

From the above mentioned viewpoints, the following functions are considered to be necessary for the precise evaluation of segregation.

1) High resolving power:

High resolving power is a premise for the abovementioned purpose. According to our previous investigation on the dimensions of segregation and solidification structures, the resolving powers of $20 \sim$ $200 \mu \mathrm{m}$ and $0.5 \sim 3 \mu \mathrm{m}$ are necessary for the evaluation of solute segregation and precipitate such as $\mathrm{MnS}$ in as-cast state, respectively. But, the total analytical time becomes acceleratively longer as the resolving power becomes better, if we hope a proper analytical accuracy. So, the appropriate resolving power, which depends on the diameter of the electron beam in the analytical system such as EPMA, should be chosen in accordance with the degree in question, and the wide selection of resolving power is desirable.

2) Quantitative analysis of segregated elements

3) High reliability with a short analytical time and the presentation of the abundant informations on spacious distribution

4) Presentation of multiple data and its visualization through computer data processing

i) Quantitative analysis on the fraction of segregated area and the size distribution of the segregation spots corresponding to the optional concentration of various segregated elements

ii) Presentation of the combined and converted data directly relating to the quality of product

iii) Accumulated screen display of many segregated elements with various display colours

iv) Zooming up of a particular part in question.

III. Principle and Basic Performance of Each New Evaluation Techniques

1. Macroanalyser $(M A)$

The schematic configuration of the analytical principle ${ }^{1,2)}$ is shown in Fig. 1. The basic principle is the same as that of EPMA. But, in order to make spacious two-dimensional analysis possible, the combination of a high speed sample driving stage and wide range electron scanning (max. $10 \times 10 \mathrm{~mm}$ square) by long focus electron beam with $20 \mu \mathrm{m}$-several millimeters in diameter is adopted, and the electron beam current is extremely intensified in comparison with that of EPMA so as to increase the X-ray emission. ${ }^{8,9)}$

On the other hand, as for the X-ray spectroscopic system, the flat crystals and the solar slit collectors, which have the high stability of X-ray reflection even when the electron beam scans in a wide range, are also adopted. Besides, graphite crystals which have the good resolving power of X-ray and the excellent reflection efficiency, is used for the analysis of important elements such as $\mathrm{P}$ and $\mathrm{S}$. Therefore, the instability of X-ray output caused by the unevenness and the curvature of the sample surface, which is apt to become trouble at the analysis of big samples, becomes negligibly small and the total analytical time can be shortened as shown in Table 2 .

In order to clarify the influence of the inclination and the coarseness of the sample surface, several typical experiments ${ }^{3}$ ) were carried out. Even at the inclination of $8 \mathrm{~mm} / 100 \mathrm{~mm}$, the display of $\mathrm{P}$ segrega-

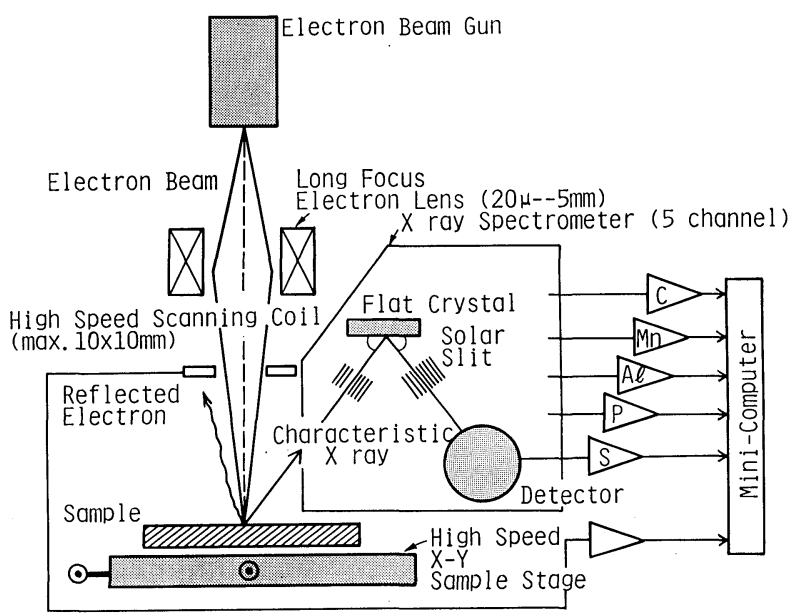

Fig. 1. The schematic configuration of Macro-analyser.

Table 2. Standard performance of MA and CMA.

\begin{tabular}{|c|c|c|c|}
\hline \multicolumn{2}{|r|}{ Items } & MA & CMA \\
\hline Sample & $\begin{array}{l}\text { Sample size } \\
\text { Sample mounting } \\
\text { Sample inclination } \\
\text { Coarseness of sample surface }\end{array}$ & $\begin{array}{l}300 \times 100 \times 10 \sim 50 \mathrm{~mm} \\
6 \text { samples (automatic exchange) } \\
\leqq 10 \mathrm{~mm} \\
\text { Fine than } \# 80 \text { (except for } \mathrm{C} \text { analysis) }\end{array}$ & $\begin{array}{l}100 \times 100 \times 10 \mathrm{~mm} \\
1 \text { sample } \\
\leqq 3 \mathrm{~mm} \\
\text { Mirror surface }\end{array}$ \\
\hline \multicolumn{2}{|c|}{ Elements and Analytical range } & $\begin{array}{l}\mathrm{C} \sim \mathrm{U}, 5 \text { channel } \\
\quad \exp .\left\{\begin{array}{l}\mathrm{C} \geqq 0.05 \% \\
\mathrm{Mn} \geqq 0.01 \% \\
P \quad \geqq 0.005 \%\end{array}\right. \\
20 \mu \mathrm{m} \sim 5 \mathrm{~mm}\end{array}$ & $\begin{array}{l}\mathrm{B} \sim \mathrm{U}, 5 \text { channel } \\
\left\{\begin{array}{l}\mathrm{C} \geqq 0.01 \% \\
\mathrm{Mn} \geqq 0.01 \% \\
\mathrm{P} \geqq 0.005 \%\end{array}\right. \\
\text { Size of picture element } \\
\quad 1 \sim 300 \mu \mathrm{m}\end{array}$ \\
\hline \multicolumn{2}{|c|}{ Electron beam current } & Max. $0.5 \mathrm{~mA}$ & $0.1 \mathrm{~mA} \sim 10^{-12} \mathrm{~A}$ \\
\hline \multicolumn{2}{|c|}{ Analysis time } & $1.8 \mathrm{hr} / 80 \times 80 \mathrm{~mm}(100 \mu)$ & $1.8 \mathrm{hr} / 80 \times 80 \mathrm{~mm}(100 \mu)$ \\
\hline
\end{tabular}


tion and the $\mathrm{P}$ concentration profile along a fixed crossing line were almost same as those of same sample horizontally fixed. The influence of the coarseness of the sample surface polished by Emery papers was negligibly small. It is also confirmed that the reproducibility is fairly excellent in each cases.

An example of the calibration curve for the $\mathrm{P}$ content $^{3)}$ is shown in Fig. 2. In general, the limit of detection (L.D) can be expressed as next equation from the viewpoint of $\mathrm{X}$-ray statistical deviation.

$$
\text { L.D }(3 \sigma)=3 \frac{\sqrt{B}}{A} \sqrt{\frac{2}{t}}
$$

where, $A$ : increment of characteristic X-ray intensity by unit change of concentration (cps/\%)

$B$ : X-ray intensity of back ground (cps)

$t$ : integration time of X-ray counting (sec).

From Eq. (1) and the data shown in Fig. 2, L.D $(3 \sigma)$ of $\mathrm{P}$ is calculated to be $0.0065 \%$ at $t=1 \mathrm{sec}$ which is smaller than $0.01 \%(3 \sigma, 1 \mathrm{sec})$ of EMPA. On the other hand, to inquire the appropriateness of Eq. (1) where the error is defined only as a statistical deviation of X-ray counting, the relation between the integral time and the standard deviation $(3 \sigma)$ of the estimated $\mathrm{P}$ content was measured. In this experiment, we analysed $\mathrm{P}$ concentration at a fixed position 1000 times and repeated the same operation for other 10 positions in each specimen with uniform $\mathrm{P}$ content of $0.002 \sim 0.48 \%$, and then calculated the standard deviation of $\mathrm{P}$ concentration for each specimen.

The result is shown in Fig. 3. The measured standard deviations are almost same as that estimated from Eq. (1), and the gradient between $\log \sigma$ and $\log t$ accords with the theoretical value. In other words, Macroanalyser has the good stability as a analytical system and the standard deviation is found to be in inverse proportion of square root of the integral time. Besides, it is found from above that Macroanalyser has an excellent detectability and accuracy in the practical evaluation of segregation.

The basic performance of Macroanalyser is listed in Table 2, together with that of Computer-aided Micro-analyser. $6 \mathrm{big}$ samples reaching to $300 \times$ $100 \times 10 \sim 50 \mathrm{~mm}$ in size can be mounted at a time and exchanged automatically one by one. The diameter and the current of the electron beam can be attenuated in a wide range of $20 \mu \mathrm{m} \sim 5 \mathrm{~mm}$ and the maximum $0.5 \mathrm{~mA}$, respectively. Therefore, Macroanalyser can respond to various analytical demands, having a good efficiency in operation and can offer reliable informations with a high representability. For the purposes of the automatic operation and the high speed processing of the great amount of data, microcomputers are installed perfectly to control the analytical system and to set the analytical conditions and so on. X-ray output is once converted into the concentration of each elements and then presented on a colour graphic display screen and a lineprinter corresponding to the optional concentration of segregated elements after various data processing and pre-

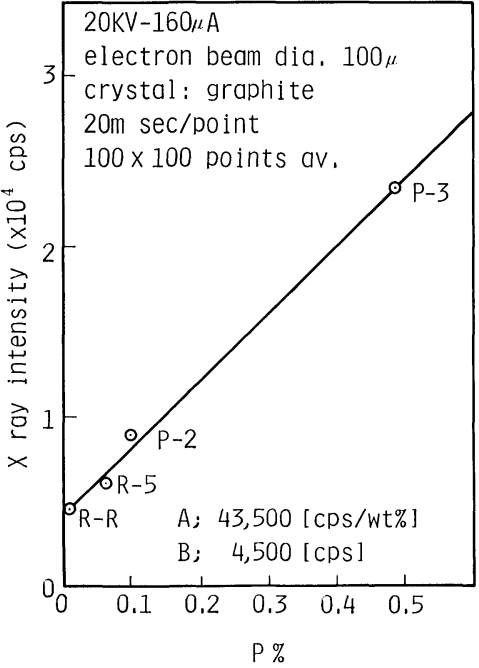

Fig. 2. An example of calibration curve for phosphorous concentration (MA).

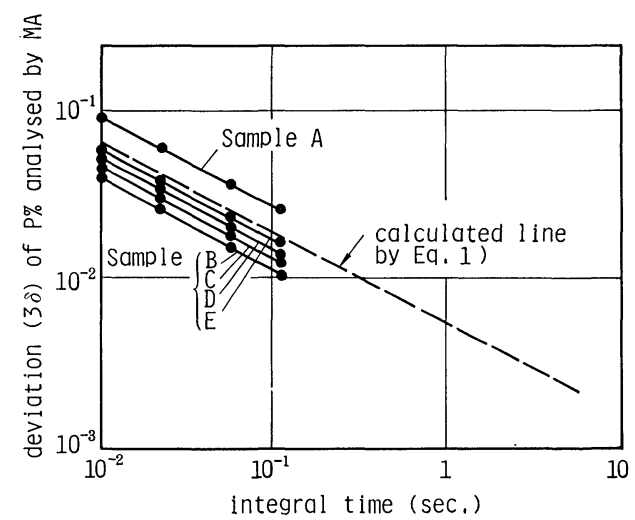

Fig. 3. The relation of integral time and deviation of observed P \% (MA).

served in a magnetic disc. As this system has also a picture analysis function, the ratio of the segregated area and the size distribution of segregation spots with various concentration can be given.

A typical example of the analytical results on the segregation in a CG slab is shown in Photo. 1. Although these photographs show the distribution of $\mathrm{Mn}, \mathrm{P}$ and $\mathrm{S}$ more than a certain concentration in the central $50 \times 50 \mathrm{~mm}$ square region around the center segregation of a longitudinal section, the segregation of $\mathrm{Mn}$ and $\mathrm{P}$ is very clearly detected with the fine resolving power. And it can be also seen that the $\mathrm{P}$ distribution almost coincides with that of $\mathrm{Mn}$ with the good reproducibility and the larger segregation spots have the tendency to remain up to higher concentration. But, S disperses uniformly because $\mathrm{Ca}$ was added for the purpose of the sulphide shape control in this case.

\section{Computer-aided Micro-analyser (CMA)}

$\mathrm{CMA}^{4,5)}$ is the new analytical appratus which consists of an EPMA and computers. Until now, an EPMA has been used only for the analysis of limited specimen surfaces less than about $0.25 \mathrm{~mm}$ square, and the analytical result is apt to be rather qualita- 


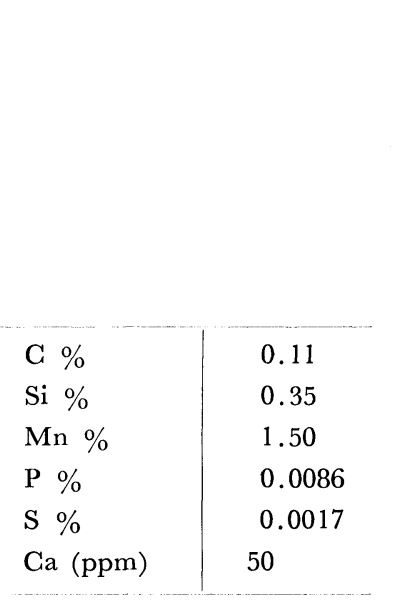

Photo. 1.

An analytical result of segregation in CG slab by Macro-analyser (Beam Dia.: $100 \mu$ ).
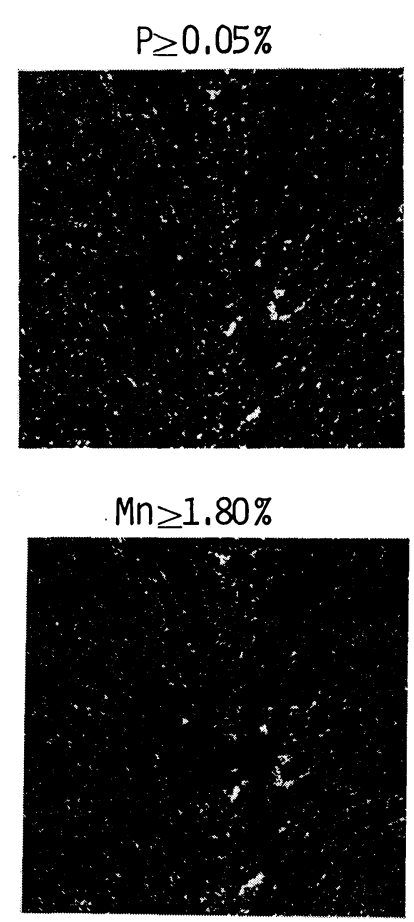
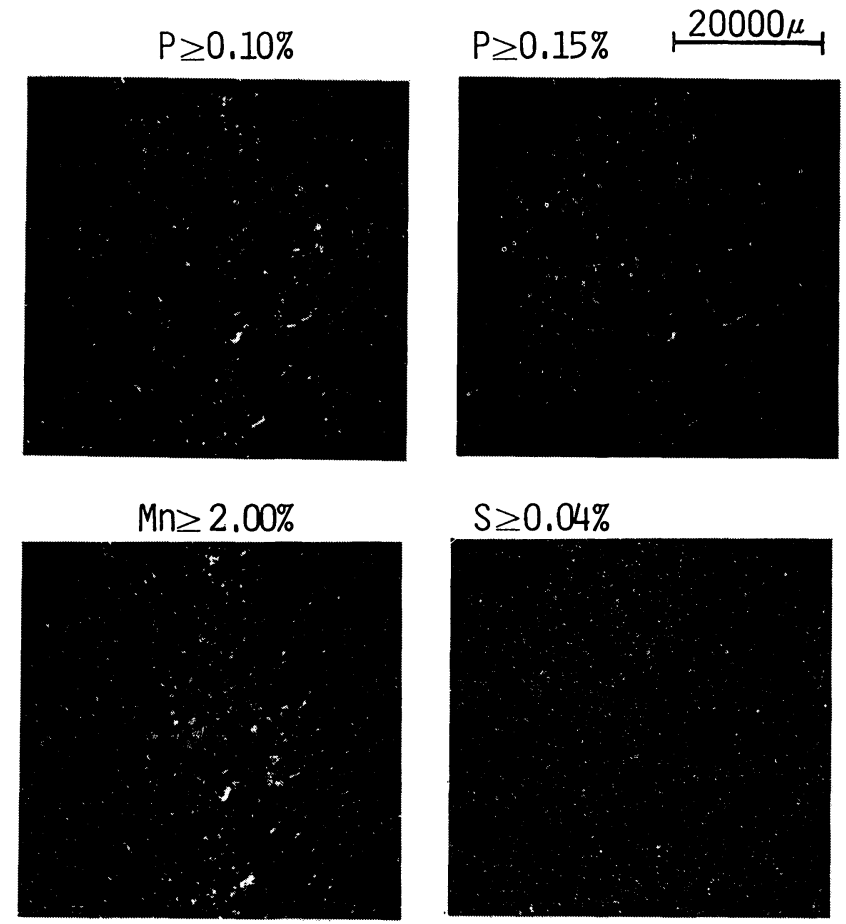

$S \geq 0.04 \%$

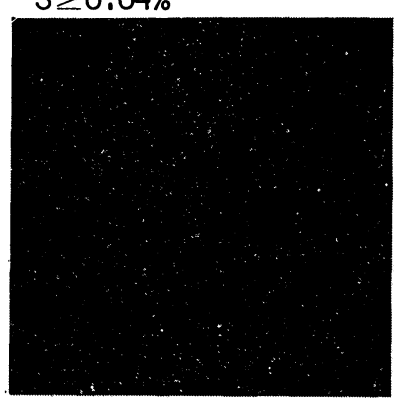

tive. Therefore, an EPMA is not necessarily sufficient to evaluate the segregation in cast steel.

GMA, on the other hand, has the quick data processing and system control by computers as shown in Fig. 4 to make various quantitative presentation for spacious specimen area (max. $80 \mathrm{~mm}$ square) possible. This analytical function is drastically developed, to have the advantage of EPMA such as the high resolving power as shown in Table 2. Namely, by the combination of the electron scanning and the high speed sample driving stage controlled by the computer, the whole analytical area is divided into many minute square elements (max. $10^{6}$ elements of $1 \sim 300 \mu \mathrm{m}$ in size), and the signal is processed for each square element. But, in these procedures, each analytical time is so short that the high sensitivity and $(\mathrm{S} / \mathrm{N})$ ratio is necessary for X-ray spectroscopy. So, wide curved spectroscopic crystals are adopted.

Besides, GMA has the compensation function for the inclination of sample surface by the automatic $Z$-axis positioning ( $\pm 3 \mathrm{~mm} \max$.). Therefore, the instability of X-ray output owing to non-focusing aberration can be minimized to the level out of the question, and CMA has the almost same accuracy and analytical faculty as MA as shown in Table 2.

The signal, basically processed by the computers installed, can be selectively output on the colour display tube (max. 16 shades), to the printer and the $X-Y$ plotter through various conversion such as from $\mathrm{X}$-ray intensity to concentration. In some cases, it is possible through the off-line computer processing to obtain

1) contour map of optional concentration etc.,

2) size distribution of segregation spots and ratio of segregated area corresponding to optional concentration, and

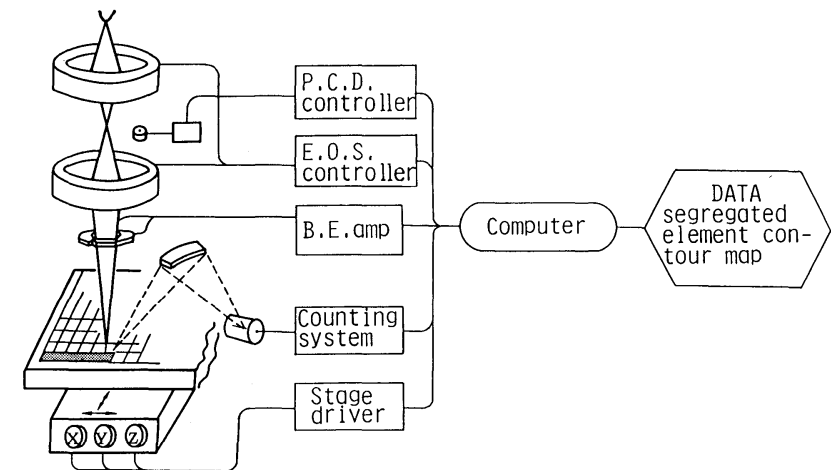

(a)

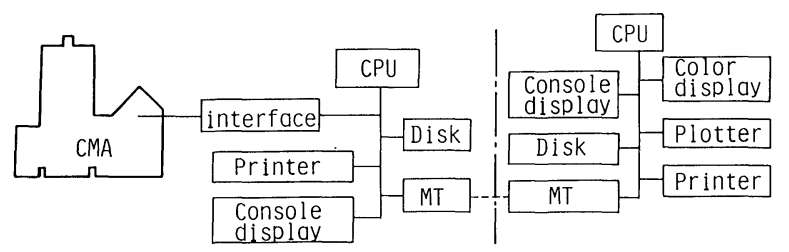

(b)

Fig. 4. The schematic configuration of Computer-aided Micro-analyser.

3) accumulated display showing the co-existence state of many elements.

From the above-mentioned viewpoints, it can be said that CMA is especially useful for the analysis of precipitates as well as segregation. An analytical result of segregation existing around the almost half thickness of CG slab is shown in Photo. 2. Photographs 2(a) to (d) show the results of rather macroscopic observation and Photos. 2(e) to (h) show the ones of microscopic observation. In the former, the distributions of $\mathrm{C}, \mathrm{P}$ and $\mathrm{S}$ seem to be almost same. But, in the latter, their distributions are found to be quite different. Namely, $S$ distributes as 


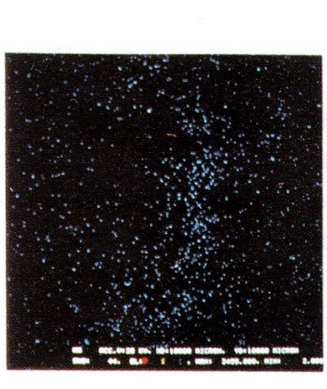

$a(C)$

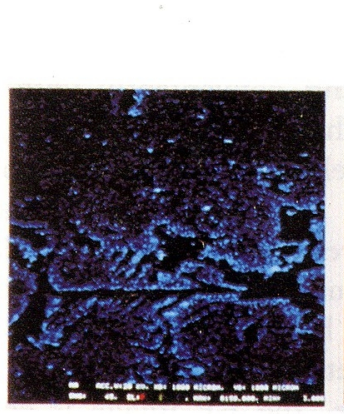

$e(C)$

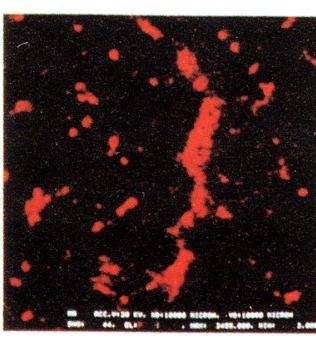

$b(P)$

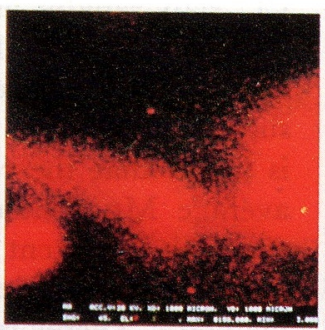

$f(P)$

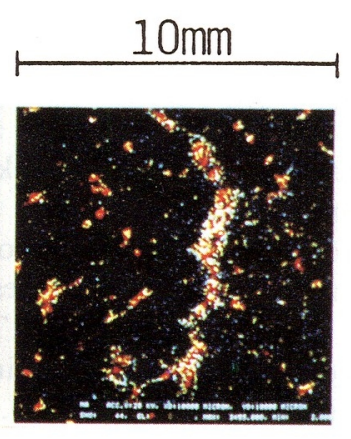

$c(S)$

$d(C, P, S)$
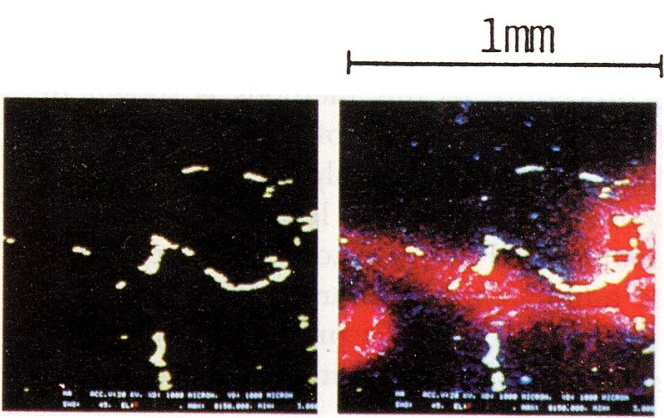

$g(S)$

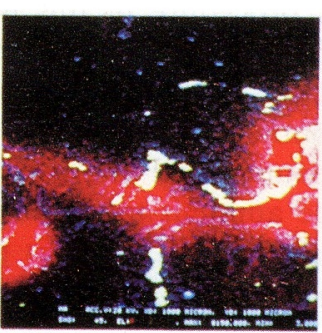

$h(C, P, S)$

Photo. 2. An analytical result of segregation in CG slab by Computer-aided Micro-analyser.

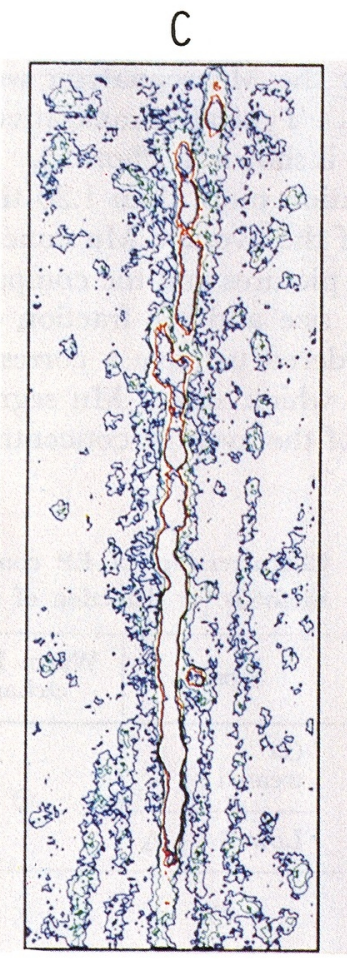

CONC.

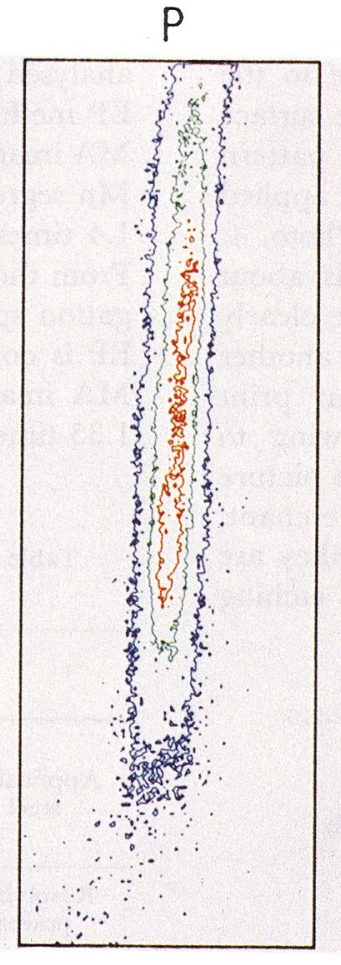

CONC.

AREA

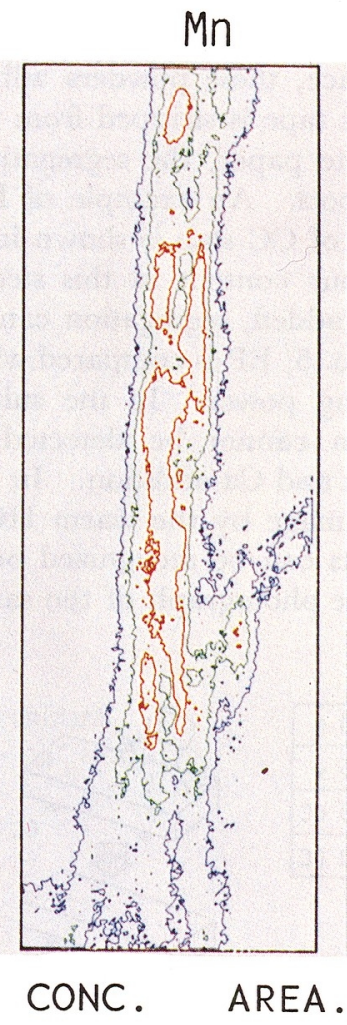

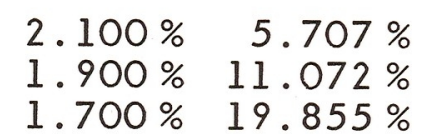
$0.900 \%$
$1.306 \%$
$0.700 \%$
$6.106 \%$
$0.160 \%$
$0.100 \%$
$1.454 \%$

$5.204 \%$
$0.040 \% 11.276 \%$

(c)

Photo. 3. Another result of Computer-aided Micro-analyser (segregation around hydrogen induced crack). 
sulphide in the phosphorous segregation and $\mathrm{C}$ segregates in the rather complicated form owing to $\gamma-\alpha$ transformation.

Another analytical result of segregation in the vicinity of hydrogen induced crack is shown in Photo. 3. The segregations of $\mathrm{C}, \mathrm{Mn}$ and $\mathrm{P}$ are clearly observed around the crack. In other words, it may be said that the crack propagates through the area where $\mathrm{C}, \mathrm{P}$ and $\mathrm{Mn}$ segregate. The propagation of the crack seems to stop at the point where the $\mathrm{P}$ and Mn concentrations are almost $0.03 \%$ and $1.80 \%$, respectively.

\section{Segregation Etch Print $(E P)^{6,7)}$}

The principle of EP differs from those of MA and CMA. The procedure of this methods is shown in Fig. 5. At first, the cross section of CG slab is ground to the same finess as that for the sulphur print method. Onto the ground surface which is levelled, picric acid solution is poured and the surface is etched about $30 \mathrm{~min}$ at the ambient temperature. With this procedure, the segregated region is preferentially etched and the appearance of the dendritic structure can be suppressed.

The etched surface is then washed by water and dried by warm air. After the special surface treatment, the etched surface is polished again by the fine Emery polishing paper of No. 1000. By this procedure, fine steel particles are filled into the etch pits. When a sheet of transparent adhesive tape is placed on the surface, these powders adhere to the tape, and when this tape is stripped from the surface and placed on white paper, the segregation pattern appears as black spots. An example of EP applied to the cross section of CG slab is shown in Photo. 4. Although the sulphur content in this steel is about $0.002 \%$ and $\mathrm{Ca}$ is added, segregation can be clearly observed. In Photo. 5, EP is compared with another method for resolving power. In the sulphur print method, segregation cannot be detected owing to low sulphur content and $\mathrm{Ca}$ addition. In the picture of the segregation image by the warm $\mathrm{HCl}$ etchant, the segregation spots can be recognized but they are dim and loose. The photograph of the same etching

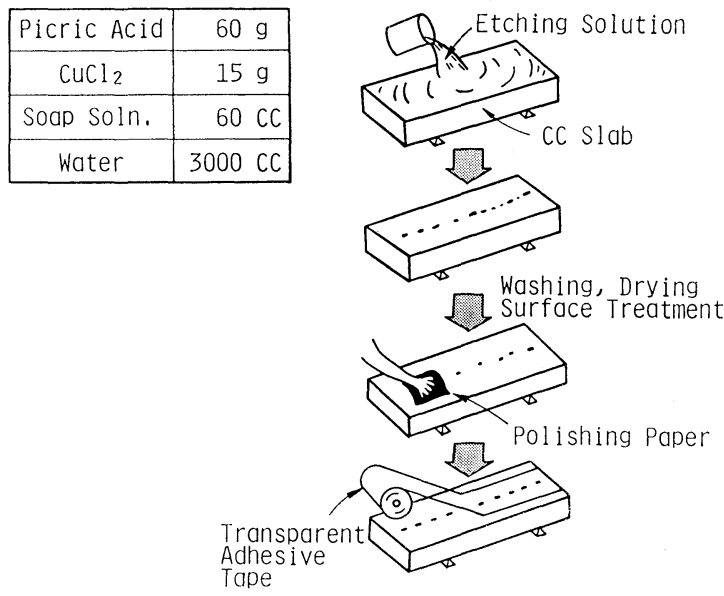

Fig. 5. Procedure of segregation etch print. surface as EP shown also poor resolving power and indistinct segregation image.

On the contrary, in the EP method, even fine spotlike segregation can be detected easily and with very good contrast. As a result of checking the reproducibility of EP, it is found that even fairly small segregation spots can be detected with an excellent reproducibility. ${ }^{6,7)}$ In addition to these features, EP can show the dendritic solidification structure under the choice of the proper etching conditions, and the fine cracks that can be hardly detected by the sulphur print or the other methods.

These characteristics of EP are summarized in Table 3. It is obvious that EP can reveal and record the segregation and so on, over a very wide area of $\mathrm{CC}$ slab rapidly and conveniently with a high resolving power. The segregation image by EP is considered to correlate to the segregation of solute such as Mn and P. But, as a result of many trials, it is found that the results of EP are unrelated to the average $\mathrm{Mn}$ content of steel. On the other hand, even the $\mathrm{P}$ content below $20 \mathrm{ppm}$ in steel is found to permit the easy detection of segregation by the EP method. Therefore, the EP image is considered to have a relation with the relative concentration difference of solute between the segregated area and the matrix, rather than with the average concentration in the specimen. Then, in order to investigate the relation between the segregation image of EP and solute segregation, the specimens which had been already analysed by the Macroanalyser were checked by the EP method. Typical comparative result of EP and MA images is shown in Photo. 6. In the MA images, Mn segregation more than 1.20 times, 1.3 times and 1.4 times of the average Mn concentration is shown. From these pictures and the comparison on the segregation spot size and the fraction of segregated area, EP is considered to have a correspondence with the MA image which shows Mn segregation over 1.3 1.35 times of the average concentration.

Table 3. Characteristics of EP compared with other methods for detection of segregation.

\begin{tabular}{|c|c|c|c|c|}
\hline & \multicolumn{2}{|c|}{ S-print } & $\begin{array}{c}\text { Warm HG1 } \\
\text { etchant }\end{array}$ & EP \\
\hline \multirow{2}{*}{$\begin{array}{l}\text { Applicable } \\
\text { steel }\end{array}$} & $\begin{array}{l}\mathrm{Ca} \\
\text { treated }\end{array}$ & $x$ & \multirow{2}{*}{0} & \multirow{2}{*}{$\mathrm{O}$} \\
\hline & Low $\mathrm{S}$ & $\Delta$ & & \\
\hline $\begin{array}{l}\text { Resolving } \\
\text { power }\end{array}$ & \multicolumn{2}{|c|}{0} & $x$ & () \\
\hline $\begin{array}{l}\text { Operation } \\
\text { time and } \\
\text { environment }\end{array}$ & \multicolumn{2}{|c|}{$90 \mathrm{~min}$} & $\begin{array}{c}150 \min \\
\times\end{array}$ & $\begin{array}{c}90 \mathrm{~min} \\
\bigcirc\end{array}$ \\
\hline $\begin{array}{l}\text { Detecting } \\
\text { ability }\end{array}$ & \multicolumn{2}{|c|}{$\begin{array}{l}\text { Segregation } \\
\text { of } \mathrm{S}\end{array}$} & $\begin{array}{l}\text { Segregation } \\
\text { of } \mathbf{C}\end{array}$ & $\begin{array}{l}\text { Segregation } \\
\text { of Mn } \\
+ \text { Fine crack }\end{array}$ \\
\hline \multirow{2}{*}{$\begin{array}{c}\text { Quantitative } \\
\text { analysis }\end{array}$} & $\begin{array}{l}\mathrm{Ca} \\
\text { treated }\end{array}$ & \multirow{2}{*}{$\times$} & \multirow{2}{*}{$\begin{array}{c}\text { Overestimate } \\
\Delta\end{array}$} & \multirow{2}{*}{$\begin{array}{c}\text { Sharp image } \\
\text { () }\end{array}$} \\
\hline & Low $\mathrm{S}$ & & & \\
\hline
\end{tabular}


Photo. 4. An example of EP applied to the cross section of CG slab.

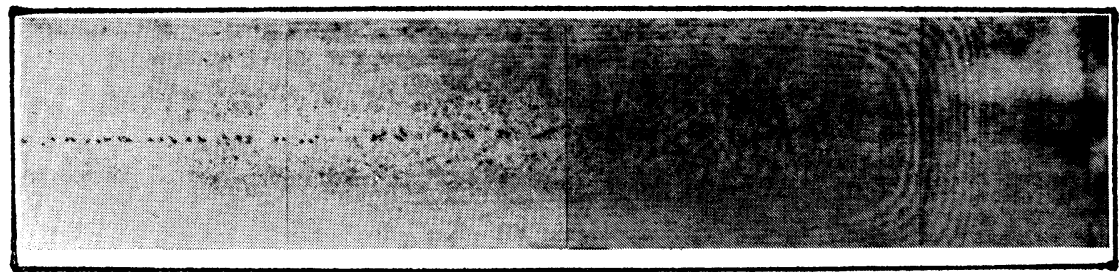

$50 \mathrm{~mm}$

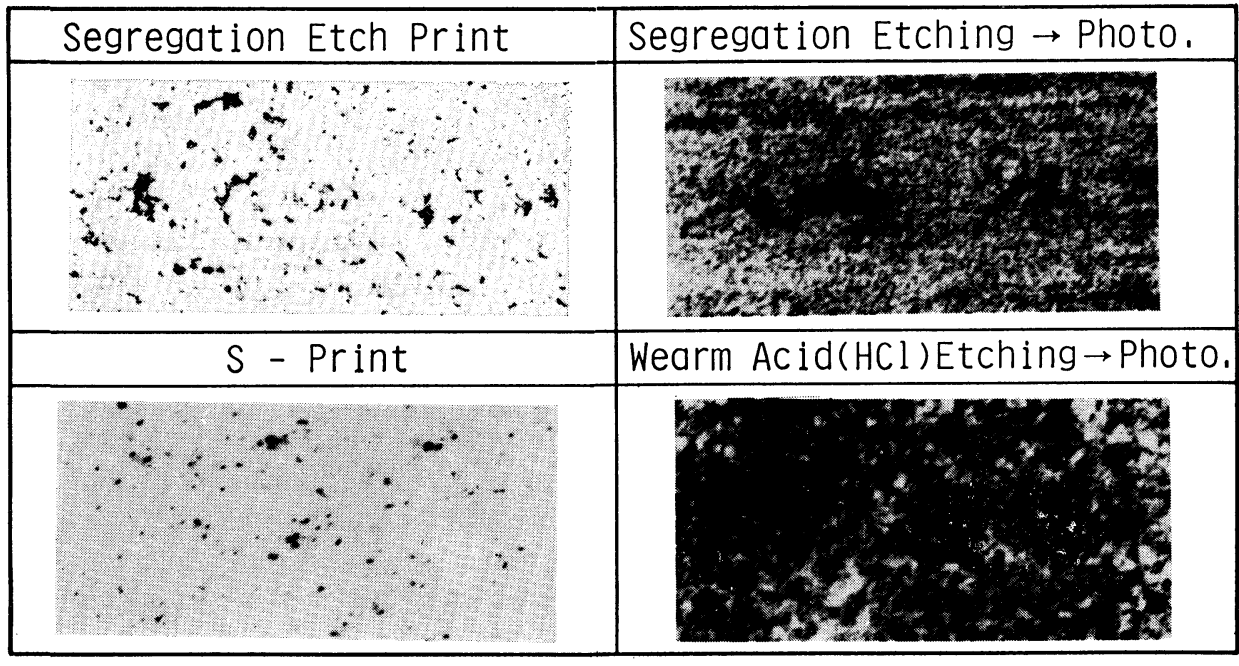

$5 \mathrm{~mm}$
Photo. 5.

Comparison of EP and ordinary methods to detect segregation and their resolving power.
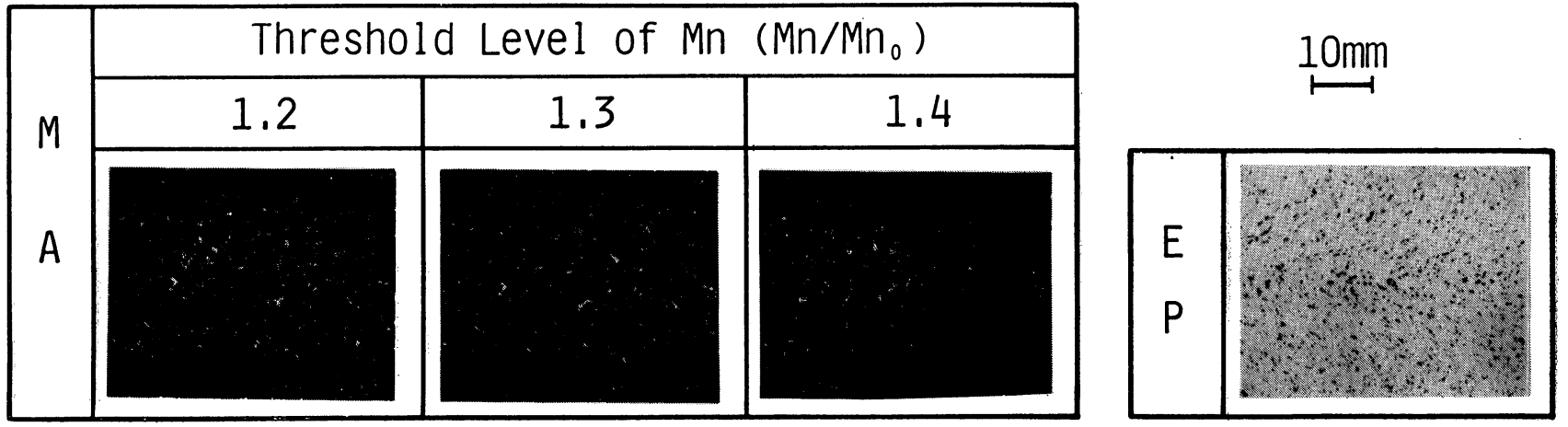

Photo. 6. Comparison of EP and the distribution of Mn segregated area observed by Macro-analyser.

\section{Practical Application of New Evaluation Techniques to the Segregation in Continu- ously Cast Steel}

The relation between the segregation in GG slabs and the welding cracks in plates of $50 \mathrm{~kg} / \mathrm{mm}^{2}$ good lamellartearing steel had been investigated by new evaluation techniques. Although conventional methods such as sulphur print and warm hydrochloric acid etching were adopted in advance to evaluate the segregation, no clear relation was found. Then, the size distribution of $\mathrm{Mn}$ segregation spots in $\mathrm{CC}$ slabs, which represents the segregation state properly, was analysed by MA. As a result, it is found that the Mn segregation spots $\left(\mathrm{Mn} / \mathrm{Mn}_{0} \geqq 1.3\right)$ larger than about $1 \mathrm{~mm}$ in the diameter of equivalent circle are obviously more numerous in the central regions of the CG slabs with welding cracks of the plates than without welding cracks as shown in Fig. 6. Therefore, it can be said that these new techniques are very useful for

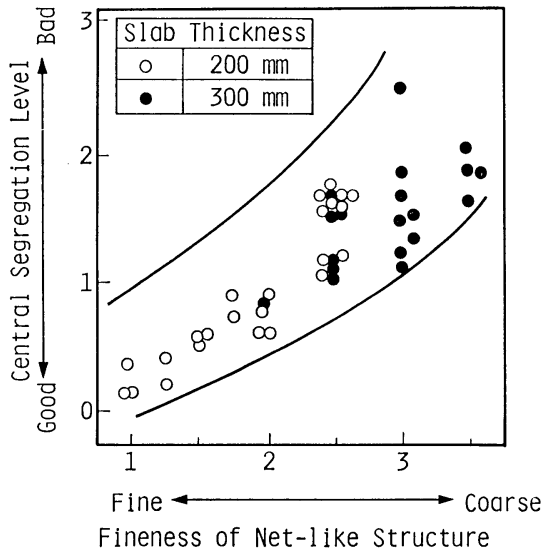

Fig. 6. The relation of welding crack in plate and the size distribution of $\mathrm{Mn}$ segregation spots in CG slabs.

the evaluation of the segregation in CG slabs and the actual conditions of the harmful one. 


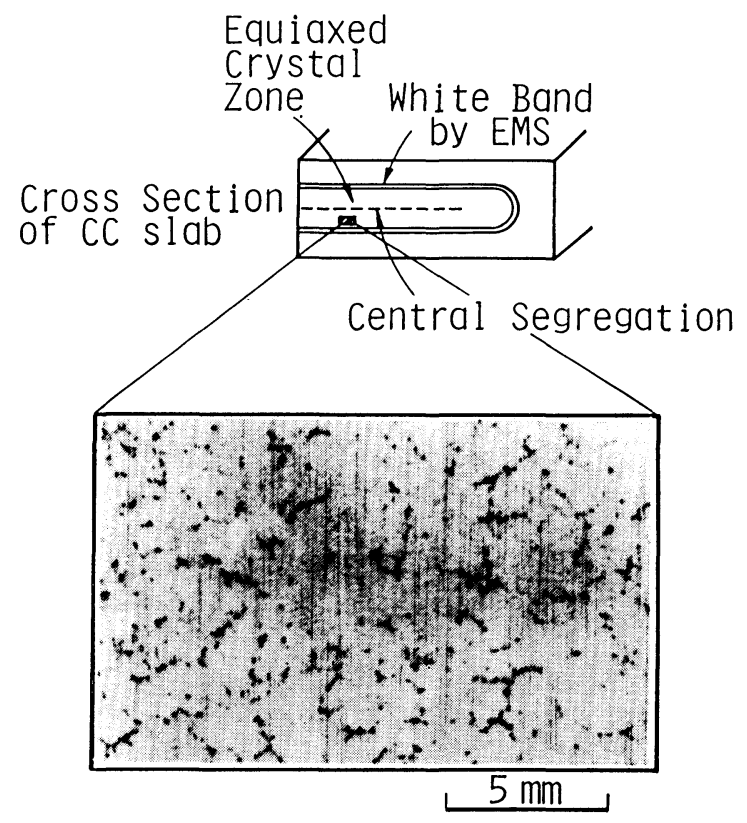

Photo. 7. Example of net-like structure in the equi-axed crystal zone.

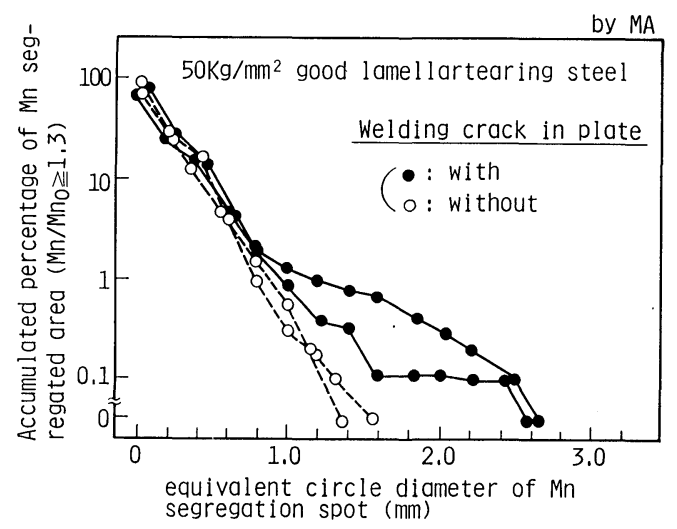

Fig. 7. Relation between the center segregation level and the fineness of net-like structure.

On the other hand, by the application of EP method, net-like solidification structure, ${ }^{7,8)}$ which could be hardly detected by the conventional methods, was observed. A typical example of net-like structure is shown in Photo. 7. According to our practical examinations, it has been found that the size of net-like structures is closely related to the center segregation and the $\mathrm{V}$-shape segregation of $\mathrm{CC}$ slabs rather than the width of equi-axial crystal zone as shown in Fig. 7. It can be controlled by the operation conditions such as the withdrawal speed and the superheat of molten steel and so on. ${ }^{8,9)}$

\section{Conclusion}

Recently, as the production of high grade steels by $\mathrm{CG}$ process is rapidly expanding, the spot-like segrega- tion, the $\mathrm{V}$-shape segregation and the sulphide existing around the almost half thickness of CG slabs come into question.

But, for the quantitative evaluation, the conventional methods such as sulphur print and warm hydrochloric acid etching are useless. Then, Macroanalyser and Computer-aided Micro-analyser based on the analytical principle of electron-probe-microanalyser were developed to be new segregation evaluation techniques instead of them.

By these developed methods, the concentration distribution of segregated elements such as $\mathrm{Mn}, \mathrm{P}$ and $\mathrm{C}$ in the relatively spacious inspection surface can be quantitatively and two-dimensionally analysed. In addition, the fraction of segregated area and the size distribution of segregation spots corresponding to the optional concentration of various segregated elements can be obtained by the computer data processing. Therefore, the segregation factors ruling the product quality and the operational conditions controlling these can be quantitatively evaluated.

In addition to these precise quantitative evaluation techniques, a segregation etch print method, by which the segregation can be easily and rapidly detected and recorded in the very broad surfaces of big specimens with an excellent resolving power, has been also developed.

This technique can reveal clearly even the segregation in low sulphur content steel or Ca added steel. So, this method seems to be very useful for the on-line quick evaluation of segregation in CG slabs and its products.

\section{REFERENCES}

1) H. Soga, K. Kawashima and K. Kitamura: Tetsu-to-Hagané, 67 (1981), S1108 \& S1109; Trans. ISIJ, 22 (1982), B135 \& B136.

2) H. Soga, K. Kawashima and K. Kitamura: Proceedings of 19th Meeting of X-ray Analysis, Japan Chem. Anal. Inst., Tokyo, (1982), 29.

3) K. Kitamura, K. Kawashima, H. Soga, I. Kobayakawa and N. Watanabe: Tetsu-to-Hagané, 68 (1982), S320; Trans. ISIJ, 22 (1982), B385.

4) I. Taguchi, H. Hamada and M. Kama: Corrected Abstracts JIM 1981 Autumn Meeting of Japan Inst. Metals, (1981), 89.

5) I. Taguchi and K. Sato: Bunseki, (1981), No. 10, 737.

6) S. Kitamura and K. Miyamura: Tetsu-to-Hagané, 68 (1982), S217.

7) K. Miyamura and S. Kitamura: "Data of the Council of Solidification Phenomena", Subcomm. 3, the 19th Committee, (Solidification), The Japan Soc. Promotion Science (JSPS), Rep. No. Solidification-324, (1982).

8) S. Kitamura, K. Miyamura, S. Sakaguchi, K. Kitamura and H. Soga: Tetsu-to-Hagané, 68 (1982), S868; Trans. ISIJ, 23 (1983), B8.

9) S. Kitamura, K. Miyamura, S. Sakaguchi and G. Hamaguchi: Tetsu-to-Hagané, 69 (1983), S264; Trans. ISIJ, 23 (1983), B409. 